\title{
(Just) in time for the holidays
}

Elaine Hall

Northumbria University, UK

Elaine.Hall@northumbria.ac.uk

This is the late-running November edition, delayed by leaves on the line/ the wrong kind of snow/ editorial inefficiency (take your pick!). I know that the fantastic content will make up for the wait.

Leslie Wolf, Stacie Kershner and Lisa Bliss start us off with their exploration of how an innovative learning experience has supported students preparing to work in Health Law, a fascinating look at the alignment of demand from the job market, student need, tailored pedagogy and specialist knowledge.

This is followed by an important reflective piece on externships from Linda Smith, Jeff Giddings and Leah Wortham, looking across practice in the USA and Australia and distilling key considerations for clinicians in developing and maintaining effective externships.

We change scale but not theme with Larry Donnelly's article on 'disorienting moments': recognising the individual and critical learning opportunities provided within clinical education and reflecting on how to recognise as teachers and convey to students these 'moments of opportunity'. 


\section{Editorial}

We stay in Ireland for the first of our practice reports, in which Sinead Eaton demonstrates the use of a contract, not simply to understand and become proficient in that example but to extrapolate from that to a broader and more holistic view of the law.

In our second practice report, Cosmos Nike Nwedu gives us a rich account of the clinic at Ebonyi State University in Nigeria, describing the history and current practice as well as the impact on local communities.

As promised, I am highlighting some of our classic papers in the second Archive Dive. Many of us are looking forward to a short break from the managerial aspects of clinic - dealing with competing demands, balancing accountability and action - and it is therefore comforting to recognise that we have been here before: $\underline{\text { Volume } 6}$ from 2004 has papers on quality (Hugh Brayne and Adrian Evans) and context (Roy Stuckey and Martin Wilson), impact (Liz Curran) and management (Ross Hyams).

We are delighted to be able to announce we are jointly holding the next IJCLE conference with Monash University in Melbourne, Australia on $28^{\text {th }}-30^{\text {th }}$ November 2018. The theme of the conference is 'Adding Value - How Clinics Contribute to Communities, Students and the Legal Profession' and a detailed call for papers will be hitting your inboxes very soon. It promises to be an excellent conference with the added bonus of the option to attend/submit a paper to the International Legal Ethics Conference $\left(6-8^{\text {th }}\right.$ December) following shortly thereafter. 